\title{
Food losses in the UK
}

\author{
By D. D. Singer, Food Science Division, Ministry of Agriculture, Fisheries and \\ Food, London SWI
}

\section{Definition of roaste}

Lord Kelvin once said '.... when you can measure what you are speaking about and express it in numbers, you know something about it; but when you cannot measure it, when you cannot express it in numbers, your knowledge is of a meagre and unsatisfactory kind'. Presumably he would have agreed that before measurement the phenomenon would have to be defined.

When we consider waste, we come immediately up against the difficulty in conceiving a definition that is unequivocal, universally applicable and acceptable to all who will use the term. This is especially so when the material under consideration is food. One reason for the difficulty is that both waste and food are so often considered subjectively rather than objectively, or personally instead of impersonally. What is waste in one context may be a raw material in another. What is waste food to the affluent European might be a feast for the starving in Africa or India. What the husband eats, the wife might discard.

Waste is one of those words that immediately creates the impression of badness, inefficiency, omission, prodigality or extravagance. It is no wonder that benevolent organizations often point to our food system with a critical finger when estimates of food waste are quoted. The subject of food waste is a complex one; whereas facile solutions for lessening the degree of waste are easy to conceive, they are not easy to apply.

Food waste has been defined (Roy, 1976) as 'a potential source of food that has knowingly been discarded or destroyed. Waste includes inedible materials that could yield food through utilization as animal feed'. He also defined food loss as 'a potential source of food that has been inadvertently destroyed or spoiled', and relative waste as 'the inefficient use of food resources in feeding say, cereals, to livestock instead of directly to people'. Clearly, these definitions have a wide scope and can give rise to large, but not immediately useful, estimates of over-all waste. However, this kind of thinking is commonly used in considerations of siege economics or nutritional doomsdays (e.g. Mellanby, $1975 a, b$ ). At a conference on food losses convened by the University of Idaho in 1976 one speaker proposed the following definition, 'food loss is defined by the edible portion of agricultural production no longer usable for human consumption or the decreased value of the commodity for the purpose of human nutrition' (Zaehringer \& Early, 1976). This definition seems to be too wide in some aspects and too narrow in others. For instance, what do we mean by 'edible'? How do we accommodate the inevitable loss of nutritional value with time after slaughter or processing of the animal or harvest of the crop? It is useful to define food waste by division into three 
categories (Singer \& Smart, 1977) as follows: food waste is the material which for any reason is not utilized for human food which is (a) intended for human consumption, or (b) which would be considered edible by the average person, or (c) which could be consumed by the average person. Although we have not always done so in the past, we now try to treat these categories as mutually exclusive.

Category (a) comprises those foodstuffs that go to make up the diet and which are accepted by most people with normal eating habits. It does not include materials such as starches, fats or gelatin, which although acceptable are actually used in industry for non-food purpose. These materials are included in category (b) which also includes certain materials used for pet-food. Category (c) is very wide since it includes all those edible materials which are not eaten because of fashion, taboo, prejudice and ignorance.

Before dealing with these types of waste in more detail, and bearing Lord Kelvin's concept in mind, we immediately encounter a further difficulty - what units should we employ? The nutritionist inevitably thinks in terms of energy. This unit is useful but can be misleading when considering low energy foodstuffs especially fruits and vegetables and at the same time it gives too much significance to fats and carbohydrates. Some nutritionists take the wider view of food waste embracing losses of all nutrients but it is difficult to conceive how such losses can be represented in terms of a unique universally applicable unit. Another possible unit is monetary-the pound sterling or dollar. One drawback of monetary measurements of waste is that the values of foodstuffs vary with time. It is also important to remember that food values vary according to their availability and demand. What the economist calls the elasticity of demand plays an important part in what quantity of food is put on the market and what steps are taken to reduce waste prior to sale (the elasticity of demand is the change in sales induced by a unit increase in price). When the elasticity of demand is $<1$, a change in the quantity of the product available will bring about a greater change in the price. If the elasticity of demand is negative the relationship between price and supply is inverted. For many foods the elasticity of demand is negative and $<_{I}$ and therefore the gross revenue goes down as the supply increases. Quoting an example from the USA, beef has an elasticity of demand of -0.42 so that an increase in supply of $0.42 \%$ leads to a price reduction of $1 \%$. Clearly there is little incentive in this situation to produce more beef or to reduce losses! The elasticities of demand in the USA for eggs, milk, potatoes and apples were $-0.23,-0.32,-0.15$ and -0.68 respectively (George \& King, I 971).

We can also measure waste by weight, volume or number of items (e.g. the number of eggs). Such units are useful when dealing with a single commodity or a group of similar commodities but statements of the total weight of food wasted have limited meaning.

\section{Examples of food waste in the United Kingdom}

Before giving examples of the various types of waste in the UK, the origin of the oft-quoted figure of $25 \%$ should be explained. This figure is derived by taking the 
Ministry of Agriculture, Fisheries and Food's calculation of the energy equivalent of the total amount of food available for human consumption (i.e., the food supply available to the market) and subtracting from it the accepted figure for the average nutritional requirements for the population, and expressing this difference as a percentage of the food available. This figure, sometimes known as the crude energy gap, has been discussed at length by Baines \& Hollingsworth (196I). It is an indirect measure of waste, and it has not yet been fully explained or substantiated. An investigation into its significance is being carried out by the Ministry's Food Wastage Study Group but the task is a daunting one, involving many disciplines, and the results will not be available for some time. It should be noted that other countries with diets and marketing and distribution patterns similar to those of the UK, provide statistics with similar crude energy gaps. There is no reason on this account to believe that the UK is unusually wasteful.

Direct measurements of food waste have been carried out from time to time in various areas, but because of the different concepts of waste and different methods of measurement it is impossible to compile a national total from them. Although the results are not yet fully available, a preliminary report of a study investigating domestic food waste of Ministry staff and their families has been published (Buss \& Wenlock, 1977). During this survey, the potentially edible food discarded amounted to about $5 \%$ of the intake (measured as energy). The waste in this survey did not include such items as outer leaves of vegetables, potato peelings, cores, skins etc., but meat bones and chicken carcasses were collected and any remaining tissues were scraped off for assessment.

The subjects were asked to record the weights and nature of food fed to pets. From information received it was calculated that $1 \%$ of food (based on intake) was fed to pets and wild birds.

A nation-wide survey has now been completed and it appears that the results will be similar to those of the smaller study. Such waste is category (a) waste.

Unfortunately no reliable figure is available by direct measurement or observation of the proportion of the food prepared or eaten outside the home in the UK. A value of $15 \%$ is usually accepted but this is derived indirectly in the course of the National Food Survey. It is commonly supposed that wastage in catering is higher than in the home but there is no real evidence that this is so. Commercial caterers and hoteliers claim that their waste is low because undue waste is so much loss of profit. In 1977 in a pilot study intended to reveal the difficulties of estimating waste in catering we studied two catering outlets. Outlet (A) was a small 'cafe' type restaurant attached to a multiple baker's shop. It was open all day for the supply of simple meals such as eggs, bacon, sausage, pastries, sandwiches etc. The other outlet (B) at a department store provided a rather more sophisticated menu including a number of three- or four-course lunches. Again the study is not yet complete but some results can be given. At establishment (A) the solid plate waste amounted by weight to $2.7 \%$ of food prepared and liquid waste amounted to $5 \%$. Kitchen waste was $6 \%$ by weight. A total of 502 customers were served during the observations. The department store restaurant (B) gave $4 \%$ solid 
plate waste and $9 \%$ liquid waste, whereas kitchen waste was $10 \%$. The higher proportion of plate waste at establishment (B) was probably due to the larger number of children and women served. (Since there is often no difference in the size of meals offered to men, women and children despite their different requirements, it follows that wastage may be higher for women and children). The food unsold at the end of the day accounted for a high proportion of kitchen waste at establishment (B). Kitchen waste was higher at this establishment because most of the items for sale were prepared by the chef in situ (e.g. scones, sausage rolls, chicken dishes etc) well in advance of demand, whereas at establishment (A) these items were brought up from the shop and the simpler meals were prepared on demand.

The waste at establishment (B) amounted to $140 \mathrm{~kJ} / \mathrm{meal}$ over a day of 2219 meals. The full input figures are not yet available in terms of energy but from what has been determined so far, it cannot be said that the waste at either of these two establishments is excessive. We want to eat at a restaurant where we get value for money and enough food to satisfy our demands. To meet all the varying demands made on him, the caterer must supply a minimum standard of quantity on the plate. It is inevitable that those with frugal appetites will be oversupplied if those with better appetites are not to be dissatisfied. Viewed in this way, the level of plate waste found is astonishingly low, especially if one takes into account the edible but unattractive items such as fat, rinds, meat remaining on bones, crusts, cores and so on.

A certain amount of over-preparation is inevitable if customers are not to be turned away because of unavailability of some items well before closing time. Some restaurants might 'carry over' food from one day to the next; neither of the two restaurants studied indulged in this practice where cooked items or sandwiches were concerned and if we want value for money, we would not want them to do so.

Space does not permit a detailed examination of catering, except for a brief mention of waste in institutional catering. There is no doubt that in some areas of institutional catering waste is high, but it is questionable whether for instance patients in hospital would be happy if meals were provided strictly in proportion to an estimated state of appetite. In schools, Bender et al. (1977) found plate waste of $10 \%$ in Brent, and Lynch (1969) found $8 \%$ plate waste in East London. More recently R. D. Howlett, R. Osner and H. M. Lyons (personal communication) found $8 \%$ plate waste in Sheffield schools. All these values are expressed in terms of weight.

Examples of category (b) waste include food materials that do not get far in the food processing-distribution chain, although the farmer might have produced them with human consumption in mind. The English bacon pig yields about $18 \%$ bone and the commercial steer $22 \%$ bone as proportion of the carcass weight (Ackroyd, 1978). After boning out, meat equivalent to about $40 \%$ of the weight of the pig bones and about $22 \%$ of the beef bones is recoverable. Although techniques are available for the recovery of the meat, the industry will only use them if assessment of the market leads to the expectation of sufficient profit to justify the 
necessary capital expenditure. The animal bones (excluding poultry) that are available from abattoirs in the UK amount to 500000-600000 tonnes/year. Approximately half of this is used for human food purposes. The remainder can be considered as waste although it may find a use as fertilizer, pet food etc. However, over-all, there is probably more category (a) waste in food processing and distribution than category (b) waste. Examples include category (b) sugars in the effluent from confectionery and preservative manufacture, perhaps as high as $10 \%$ of purchases and category (a) bread unsold or returned to bakeries, fruit and vegetables lost by damage at any stage and milk remaining in tankers after pumping. Whether these examples are in category (a) or (b) still remains to some extent a subjective view.

Turning to category (c) waste we see that a considerable amount of food material of nutritional value is discarded from the human food chain. Taking abattoir waste as an example, it is estimated that about 100000 tonnes of animal blood is available annually in the UK. Of this only 900 tonnes are utilized for human food. 21000 tonnes are used in pet foods, and a further 29000 tonnes used for other purposes, but 49000 tonnes go to the sewers. These figures are quoted from a study that was recently completed by the British Food Manufacturers Research Association on behalf of the Ministry. The report shows that very large quantities of animal organs which find acceptable uses in other European countries are diverted in the UK from the human food chain. One major reason for this is the peculiar dislikes or taboos that exist among various populations. During wartime years, people were happy to eat lung, but this organ is seldom displayed on the butcher's counters these days, and it is doubtful whether it would have a wide sale. Udders were once considered a delicacy, but nowadays are restricted to a few localities. Once we were happy to wash greenfly from lettuce; today we would probably refuse to buy such a lettuce supposing the greengrocer were brave enough to sell it; even if we did so, we would be likely to consign it directly to the wastebin or compost heap. Spider crabs caught by British fishermen are exported since there is no market for them here. As a nation we do not eat horsemeat, frogs, insects and many types of eggs that others consume. Are such items to be considered as waste or not?

If we restrict our view of waste to category (a) we can conceive a system or society where waste would be reduced. In such a world, the shops would run out of perishable food early in the day, restaurants would provide a restricted menu, some customers would leave the table unsatisfied, the food industry would produce a limited variety of foods and would find it difficult to make any profit. We waste food for economic and personal reasons and because we become increasingly fastidious as we become more affluent. The reduction of waste is possible and desirable, but attempts to reduce waste must take account of the human and economic factors; in the end it is a matter of value for money! 


\section{REFERENCES}

Ackroyd, H. B. (1978). Proceedings of Meat and Livestock Commission Seminar, May. Recovering Meat from Bones.

Baines, A. H. J. \& Hollingsworth, D. (196I). Family Living Studies-A Symposium. A Survey of Food Consumption in Great Britain, ILO, Geneva.

Bender, A. E., Harris, M. C. \& Getrever, A. (1977). Br. med. f. 1, 757.

Buss, D. H. \& Wenlock, R. (1977). J. hum. Nutr. 31, 405.

George, P. S. \& King, G. A. (1971). Consumer Demand for food commodities in the US. Giannini Federation Monograph 26, University of California.

Lynch, G. W. (1969). The Medical Officer $121,39$.

Mellanby, K. (1975a). Can Britain feed itself. Merlin Press.

Mellanby, K. (1975b). Losing Ground. London: Earth Resources Research Ltd.

Roy, R. (1976). Wastage in the UK Food System. London: Earth Resources Research Ltd.

Singer, D. D. \& Smart, G. A. (1977). Nutr. Fd Sci. 49, 6.

Zaehringer, M. V. \& Early, J. O. (1976). Proceedings of National Food Loss Conference, University of Idaho Boise, USA. 